\title{
THE EFFECT OF ELECTRIC FORCE ON THE MATERIAL OF STEAM BOILERS.
}

Dear SIR:-In the November number of the JourNal, which has just reached me, I have been attracted by your note on page 345 , following Dr. Cresson's paper " on the effect of magnetic and galvanic forces upon the strength of, and destruction of iron and steel structures." The notion that the destruction of iron boilers by corrosion when supplied with ordinary water is ascribable to galvanic action, has, in my opinion, very little foundation in fact. Some samples of iron corrode more readily than other samples, but they will do so when submitted to any of the conditions favorable to such slow combustion. In my experience as a locomotive engine builder and more recent observations $I$ have never seen any good reason to abandon the common practice of uniting metals of known different electro-conditions in one structure, and will cite what you must have overlooked as you do not mention it in your note, viz.: the use of cast iron boiler heads, cast iron man-hole rings in connection with wrought iron shells. Also in locomotive practice of wrought iron boilers with copper tubes, and even copper fire boxes. Some such boilers being of undoubted long life. So with many instances of boilers with brass tubes and all the fittings such as hand hole plugs are made of brass. I imagine that any of these metals so placed in connection with one another as to form a galvanic battery of usual construction, and then immersed in a bath of such water as is usually used in boilers, that the electric or galvanic currents obtainable from such, a construction would be a very feeble and that no "strong galvanic action" would take place. I like to see all theories substantiated by facts, but the facts should be viewed equally not unequally. Electricity is dragged in too of ten to account for phenomena that could be explained in other ways. You are quite right in saying that "it is a serious mistake to admit as a popular utterance, that we must look to 'galvanic (voltaic ?) force' as the cause of deteriorations of boilers, or of iron structures of any kind." I do not wish to say that it has nothing to do with it under certain conditions, but that it plays any such important part as to make us avoid combinations of metal of great mechanical advantage when combined, for fear that some grand galvanic action will destroy the structure so built up, when we all know well enough that such combination of dissimilar metals have stood the test of years, and will continue to be used with safety in good engineering practice.

3301 Baring St., Nov. 5, 1875.

Coleman Shllers.

Errata.-It will be noticed that the number of this Journal on the cover is 600 in place of 599, in (regular sequence). There was an error committed in August and September, 1870, both of which were numbered 536 , and this correction is now made 80 that the next year shall commence properly, number 601 , there having been 600 numbers actually completed by this present one.

Correct page 358 , lines 21 and 22 , for $A,-A,-A$, read $N,-N,-N$. 